\title{
Video-supported Analysis of Beggiatoa Filament Growth, Breakage, and Movement
}

\author{
Anja Kamp • Hans Røy $\cdot$ Heide N. Schulz-Vogt
}

Received: 22 April 2007 / Accepted: 27 January 2008 /Published online: 12 March 2008

(C) Springer Science + Business Media, LLC 2008

\begin{abstract}
A marine Beggiatoa sp. was cultured in semisolid agar with opposing oxygen-sulfide gradients. Growth pattern, breakage of filaments for multiplication, and movement directions of Beggiatoa filaments in the transparent agar were investigated by time-lapse video recording. The initial doubling time of cells was $15.7 \pm 1.3 \mathrm{~h}$ $($ mean \pm SD) at room temperature. Filaments grew up to an average length of $1.7 \pm 0.2 \mathrm{~mm}$, but filaments of up to approximately $6 \mathrm{~mm}$ were also present. First breakages of filaments occurred approximately $19 \mathrm{~h}$ after inoculation, and time-lapse movies illustrated that a parent filament could break into several daughter filaments within a few hours. In $>20 \%$ of the cases, filament breakage occurred at the tip of a former loop. As filament breakage is accomplished by the presence of sacrificial cells, loop formation and the presence of sacrificial cells must coincide. We hypothesize that sacrificial cells enhance the chance of loop formation by interrupting the communication between two parts of one filament. With communication interrupted, these two parts of one filament can
\end{abstract}

Electronic supplementary material The online version of this article (doi:10.1007/s00248-008-9367-x) contains supplementary material, which is available to authorized users.

A. Kamp $\cdot$ H. N. Schulz-Vogt

Institute for Microbiology, Leibniz University of Hannover,

Hannover, Germany

A. Kamp $(\varangle) \cdot$ H. Røy $\cdot$ H. N. Schulz-Vogt

Max Planck Institute for Marine Microbiology,

Bremen, Germany

e-mail: akamp@mpi-bremen.de

H. Røy

Center for Geomicrobiology, Department of Biological Sciences,

University of Aarhus,

Aarhus, Denmark randomly move toward each other forming the tip of a loop at the sacrificial cell.

\section{Introduction}

The filamentous, colorless sulfur bacteria of the genus Beggiatoa (Thiotrichales) were named after the Italian medic and botanist F. S. Beggiato [27]. Originally, they had been described as a colorless cyanobacterium named "Oscillatoria alba" nearly 40 years earlier [28]. In addition to the morphological resemblance of the filamentous genera Beggiatoa and Oscillatoria, similarities in life cycle and gliding motility were found $[6,7,12,13,16,24]$. The filaments often rotate as they move by gliding, and it was discussed that pores that have been found in parallel rows on the surface of the cells of Beggiatoa and Oscillatoria were involved in the rotating gliding motility by excretion of slime $[8,13]$. The slime surrounds the entire filament and becomes a sheath, from which gliding filaments can also be displaced or pressed out $[8,15]$.

Gliding motility is used by Beggiatoa to track their chemical microenvironment, the interface between oxygen and sulfide [26]. They grow in many aquatic habitats, e.g., at the surface and in the suboxic zone of sulfide-rich marine and freshwater sediments [10,21, 25], in hypersaline ponds [4], at hydrothermal vents [5, 9], at cold seeps [14], and on scleractinian corals infected by the black-band disease [20]. Beggiatoa can be enriched from their natural habitat in oxygen-sulfide gradient tubes [17] and sustained for several years.

In this study, cultivation in transparent agar was used in combination with time-lapse video recording to investigate the growth and multiplication of Beggiatoa under conditions, which mimicked essential aspects of the niche of 
this bacterium. These aspects include opposed gradients of oxygen and sulfide, and a physical substrate that allows gliding of filaments to their preferred microenvironment. The experimental approach was used to address the following questions. (1) What is the growth pattern of Beggiatoa filaments? (2) What is the time course of filament breakage for multiplication? (3) What are the movement directions of filaments?

\section{Methods}

\section{Sampling and Cultivation}

The 6.3- $\mu \mathrm{m}$ wide, vacuolated Beggiatoa sp. used for this study originated from a microbial consortium associated with the black-band disease of scleractinian corals (Florida Keys). The Beggiatoa filaments were enriched and kept in stable gradient cultivation for more than 6 years.

For all experiments, the Beggiatoa enrichment was cultured in agar gradient cultures, modified after Nelson and Jannasch [17]. These gradient cultures contained two layers of media, a layer of bottom agar medium $(0.75 \%$ Bacto Agar [Difco Laboratories]) containing a high sulfide concentration overlaid by a layer of softer top agar medium $(0.25 \%)$ without sulfide, which led to opposing gradients of sulfide and oxygen in the top agar. The compositions of the artificial seawater, nutrient solutions, vitamin solutions, and agar

Table 1 Composition of artificial seawater, mineral solution, trace solution, and vitamin solution

\begin{tabular}{|c|c|}
\hline $\begin{array}{l}\text { Artificial } \\
\text { seawater } \\
\text { or solution }\end{array}$ & Composition \\
\hline $\begin{array}{l}\text { Artificial } \\
\text { seawater }\end{array}$ & $\begin{array}{l}27.5 \mathrm{~g} \mathrm{NaCl}, 10.7 \mathrm{~g} \mathrm{MgCl}_{2} \cdot 6 \mathrm{H}_{2} \mathrm{O} \\
4.1 \mathrm{~g} \mathrm{MgSO}_{4} \cdot 7 \mathrm{H}_{2} \mathrm{O}, 0.66 \mathrm{~g} \mathrm{CaCl}_{2} \cdot 2 \mathrm{H}_{2} \mathrm{O} \\
1.02 \mathrm{~g} \mathrm{KCl}_{1}, 000 \mathrm{~mL} \text { distilled water }\end{array}$ \\
\hline Mineral solution & $\begin{array}{l}555 \mathrm{mg} \mathrm{K}{ }_{2} \mathrm{HPO}_{4}, 50 \mathrm{mg} \mathrm{Na} \mathrm{MoO}_{4} \\
750 \mathrm{mg} \mathrm{Na} \mathrm{S}_{2} \mathrm{O}_{5}, 29 \mathrm{mg} \mathrm{FeCl} 3 \cdot 6 \mathrm{H}_{2} \mathrm{O} \\
1,000 \mathrm{~mL} \text { distilled water }\end{array}$ \\
\hline $\begin{array}{l}\text { Trace element } \\
\text { solution }\end{array}$ & $\begin{array}{l}5.2 \mathrm{~g} \mathrm{EDTA}, 1.5 \mathrm{~g} \mathrm{FeCl}_{2} \cdot 4 \mathrm{H}_{2} \mathrm{O}, 0.07 \mathrm{~g} \mathrm{ZnCl} \\
0.1 \mathrm{~g} \mathrm{MnCl}_{2} \cdot 4 \mathrm{H}_{2} \mathrm{O}, 0.062 \mathrm{~g} \mathrm{H}_{3} \mathrm{BO}_{4}, 0.19 \mathrm{~g} \\
\mathrm{CoCl}_{2} \cdot 6 \mathrm{H}_{2} \mathrm{O}, 0.017 \mathrm{~g} \mathrm{CuCl}_{2} \cdot 2 \mathrm{H}_{2} \mathrm{O}, 0.024 \mathrm{~g} \\
\mathrm{NiCl}_{2} \cdot 6 \mathrm{H}_{2} \mathrm{O}, 0.036 \mathrm{~g} \mathrm{Na} \mathrm{MoO}_{4} \cdot 2 \mathrm{H}_{2} \mathrm{O}, \\
1,000 \mathrm{~mL} \text { distilled water }\end{array}$ \\
\hline $\begin{array}{l}\text { Vitamin stock } \\
\text { solution }^{\mathrm{a}}\end{array}$ & $\begin{array}{l}1 \mathrm{mg} \mathrm{B} 12,1 \mathrm{mg} \text { Inositol, } 1 \mathrm{mg} \text { Biotin, } \\
1 \mathrm{mg} \text { Folic Acid, } 10 \mathrm{mg} \text { PABA, } 100 \mathrm{mg} \\
\text { Nicotinic Acid, } 100 \mathrm{mg} \text { d-Pantothenate, } \\
200 \mathrm{mg} \text { Thiamine (each vitamin was dissolved } \\
\text { in } 10 \mathrm{~mL} \text { distilled water) }\end{array}$ \\
\hline
\end{tabular}

${ }^{\mathrm{a}}$ For the final vitamin solution, $1 \mathrm{~mL}$ of each vitamin stock solution was added to $100 \mathrm{~mL}$ (final volume) of distilled water
Table 2 Composition of agar media

\begin{tabular}{ll}
\hline Agar media $^{\mathrm{a}}$ & Composition \\
\hline Bottom agar medium $^{\mathrm{b}}$ & $180 \mathrm{~mL}$ artificial seawater, $1.35 \mathrm{~g}$ agar \\
Top agar medium $^{\mathrm{b}}$ & 1) $240 \mathrm{~mL}$ artificial seawater, $4.32 \mathrm{~g} \mathrm{NaCl}$ \\
& 2) $96 \mathrm{~mL}$ distilled water, $0.9 \mathrm{~g}$ agar \\
& 3) $24 \mathrm{~mL}$ mineral solution, $0.36 \mathrm{~mL}$ \\
trace solution
\end{tabular}

${ }^{\mathrm{a}}$ Each medium was autoclaved

${ }^{b}$ The three components of the top agar medium were combined after they were autoclaved

media are shown in Tables 1 and 2. The $\mathrm{pH}$ of the top agar was adjusted to approximately 8 with $\mathrm{KOH}$. The autoclaved bottom agar medium was adjusted to $4 \mathrm{mmol} / \mathrm{L} \mathrm{Na}_{2} \mathrm{~S}$. The autoclaved top agar medium was adjusted to $4 \mathrm{mmol} / \mathrm{L}$ $\mathrm{NaHCO}_{3}$, and $0.04 \%$ sterile vitamin solution was added. The gradients were prepared in screw-cap tubes (length $150 \mathrm{~mm}$, inside diameter $14 \mathrm{~mm}$ ). The tubes were filled with $4 \mathrm{~mL}$ of final bottom agar medium and $8 \mathrm{~mL}$ of top agar medium. The screw caps were left loose to permit exchange of the headspace gas with the atmosphere. To allow gradient development, the agar was aged for at least 2 days before inoculation. For the different experiments, Beggiatoa filaments were inoculated approximately $5 \mathrm{~mm}$ below the agar surface with a sterile Pasteur pipette. Cultures used for determination of protein content and filament length were grown at room temperature in the dark. Cultures used for time-lapse movies were kept in monochromatic red light (see below).

\section{Protein Determination}

The protein content of the Beggiatoa enrichment was quantified by the Coomassie Brilliant Blue assay (BioRad, Munich, Germany) of Bradford [2]. The inoculum for replicate cultures was harvested from 23 Beggiatoa enriched culture tubes; pooled, thoroughly mixed, and identical subsamples $(100 \mu \mathrm{L})$ were used for inoculation of new gradient tubes. Sets of six cultures were taken after $1,2,3,4,6,8,10,12$, and 14 days, and the top 1.5-2.5 mL agar, which contained the Beggiatoa enrichment, was harvested. Before protein measurement, the samples were incubated with $10 \%(w / v)$ trichloracetic acid at $90^{\circ} \mathrm{C}$ for $20 \mathrm{~min}$ [18], then cooled to $4^{\circ} \mathrm{C}$ overnight and centrifuged at $20,800 \times \mathrm{g}$ for $10 \mathrm{~min}$ at $4^{\circ} \mathrm{C}$. After the supernatant was removed, $1 \mathrm{~mL}$ of $0.1 \mathrm{~mol} / \mathrm{L} \mathrm{NaOH}$ was added to the pellet and heated to $55^{\circ} \mathrm{C}$ for $20 \mathrm{~min}$. Equivalent volumes of agar from uninoculated gradient tubes were processed likewise and served as blanks; bovine plasma albumin was used as the standard (Bio-Rad). The final assay mix contained $0.4 \mathrm{~mL}$ standard (in $0.1 \mathrm{~mol} / \mathrm{L} \mathrm{NaOH}$ ) or supernatant of samples, $0.4 \mathrm{~mL} 0.15 \mathrm{~mol} / \mathrm{L} \mathrm{HCl}$, and $0.2 \mathrm{~mL}$ dye reagent 
concentrate. Optical density $\left(\mathrm{OD}_{595}\right)$ of standards and samples was measured after 15 min against the blank.

\section{Camera System}

The gradient cultures were imaged from the side every 10 to $20 \mathrm{~s}$ with a Sony XCD-X710 digital monochrome camera $(1024 \times 768$ pixels $)$. Illumination was provided with a red $1 \mathrm{~W}$ Luxeon ${ }^{\mathrm{TM}}$ Star LED with collimating optics. The LED emits light in a narrow band around $625 \mathrm{~nm}$ that does not affect the movement of Beggiatoa [16]. Cultures were filmed several days and the images were collected to timelapse movies using the computer program VideoMach (Gromada Multimedia, Cologne, Germany).

\section{Initial Doubling Time of Cells}

The doubling time of cells was determined with time-lapse movies from three independent culture tubes. Single Beggiatoa filaments were inoculated into new gradient tubes. The time-lapse movies were screened for images on which the Beggiatoa filaments glided parallel to the image plane of the camera. Beggiatoa filament lengths were measured on the chosen images (movie 1: $n=8$; movie 2: $n=29$; movie $3: n=19$ ) with the free computer program UTHSCSA Image Tool (IT; University of Texas Health Science Center at San Antonio, TX, USA) until the first filament breakages occurred (approximately $19 \mathrm{~h}$ ). Filament lengths were converted into a number of standard cells (average length $=2.7 \mu \mathrm{m}$ [The average cell length of standard cells was calculated via counting all cells of a sulfur-depleted Beggiatoa filament with known length]). The number of standard cells was plotted against the time elapsed between the individual images. The functions of the exponential plots (movie 1: $r^{2}=0.98$; movie 2: $r^{2}=0.76$; movie $3: r^{2}=0.88$ ) were used to calculate the doubling time.

\section{Filament Length}

In addition to the filament length determination on the movie images, which was used to calculate the doubling time of cells, filament lengths were also measured using light micrographs of Beggiatoa on objective slides with the computer program IT. Incubation start and inoculum were the same as for the protein determinations (see above), but samples were taken in daily intervals. The Beggiatoa filaments were harvested from one gradient culture per day with a Pasteur pipette. Using a stereomicroscope, care was taken to avoid damaging filaments during the harvest. Harvested filaments were put on an objective slide for taking the light micrographs of randomly chosen Beggiatoa filaments at 100-fold magnification $(n=42)$.

\section{FISH/DAPI}

Fluorescence in situ hybridization (FISH) was performed using published methods [1,22] modified as follows. Beggiatoa filaments were taken from gradient cultures 2 days after inoculation. The filaments were fixed in $1 \mathrm{~mL}$ of freshly prepared paraformaldehyde $(4 \%)$ for $4 \mathrm{~h}$ and washed two times in $1 \times$ phosphate-buffered saline (PBS) before storage in $0.5 \mathrm{~mL}$ of $1 \times \mathrm{PBS}$ and $0.5 \mathrm{~mL}$ of $96 \%(v / v)$ ethanol. Prepared filaments were spotted on hybridization wells of non-coated microscopic slides and dried at $48^{\circ} \mathrm{C}$ before dehydration in a 50-80 $96 \%(v / v)$ ethanol series. To each well, $9-\mu \mathrm{L}$ hybridization buffer ( $35 \%$ formamide) and $1-\mu \mathrm{L}$ Cy3-labeled EUB338-III probe [3] was added. Hybridization was carried out at $46^{\circ} \mathrm{C}$ for $90 \mathrm{~min}$. After hybridization, the slides were rinsed and incubated with preheated washing buffer $\left(48^{\circ} \mathrm{C}\right)$ for $15 \mathrm{~min}$. Finally, the slides were carefully washed with $\mathrm{H}_{2} \mathrm{O}_{\text {dist }}$ and air-dried. Approximately $20 \mathrm{~min}$ before microscopic analysis, the slides were mounted in Citifluor-DAPI $\left(4^{\prime}, 6^{\prime}\right.$,-diamidino-2phenylindole). Fluorescence micrographs were recorded with a Zeiss Axiovert $200 \mathrm{M}$ microscope with apotome (545 nm excitation wavelength for FISH and $375 \mathrm{~nm}$ for DAPI).

\section{Filament Gliding Speed}

Measurements of gliding speed of Beggiatoa filaments were obtained from the same time-lapse movies that were used for the determination of the doubling time of cells. The time-lapse movies were screened for sequences in which the filament or at least tips of filaments glided parallel to the image plane of the camera. Single images $(n=757)$ of the chosen movie sequences $(n=61)$ were analyzed by marking the position of the filament tip image by image and saving its $x / y$ coordinates with the computer program IT. Distances between the $x / y$ coordinates from one to another image were calculated, summed-up, and divided by the total duration of each sequence.

\section{Filament Breakage and Movement}

Time-lapse movies were screened for sequences in which filament breakage was well visible. Filament lengths before and after their first three to four breakages were measured in three independent movies as described above. Further, 64 breakages were observed in seven independent time-lapse movies, and the direction of movement of the dividing filaments was determined. 


\section{Results}

Growth

After the Beggiatoa enrichment was inoculated, it started growing and a thin mat of well-visible Beggiatoa filaments was formed a few millimeters below the agar surface. The mat is known to occur slightly above the oxygen-sulfide interface, and it moved upward with time because biological sulfide oxidation by the Beggiatoa enrichment rendered the sulfide and oxygen gradients steeper [11, 18]. Subsequently, the Beggiatoa filaments had to move upward to remain at the oxygen-sulfide interface.

The average total protein content of the inoculum was $0.9 \pm 0.3 \mu \mathrm{g}$ (standard error [SE]; $n=6$ ) and increased linearly to $8.8 \pm 0.7 \mu \mathrm{g}$ protein during the incubation time of 2 weeks (Fig. 1). For the early growth phase (up to approximately $19 \mathrm{~h}$ after inoculation), an initial doubling time of Beggiatoa cells was calculated with $15.7 \pm 1.3 \mathrm{~h}$ from three independent culture tubes at room temperature.

\section{Filament Length Determination}

The average filament length in the inoculum was $0.7 \pm$ $0.1 \mathrm{~mm}$, which increased to $1.7 \pm 0.2 \mathrm{~mm}$ on day 7 , and remained constant thereafter (Fig. 2a). The frequency distribution of classes of filament lengths (Fig. 2b,c) revealed that filaments of up to $2 \mathrm{~mm}$ dominated the gradient culture numerically both during the early and the later incubation period (day $1-5$ and 6-14, respectively;

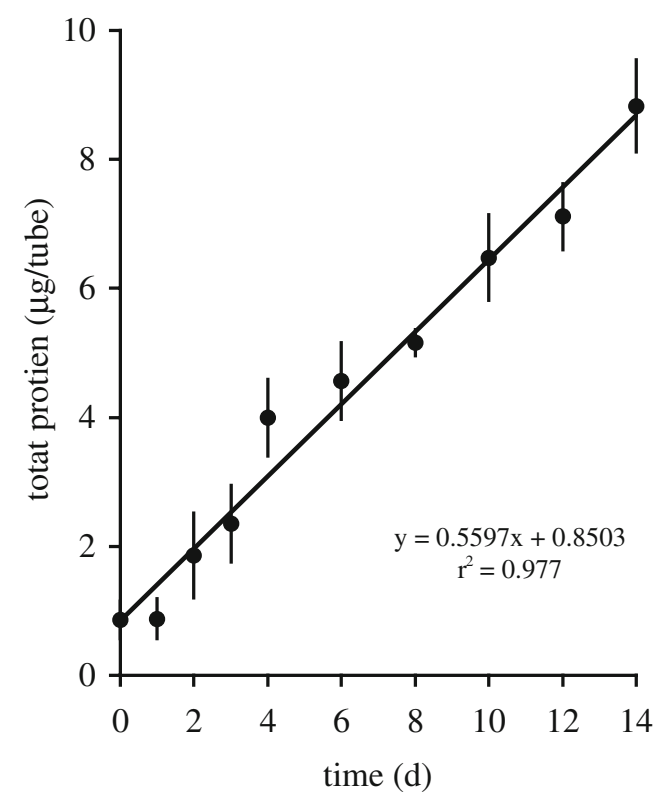

Figure 1 Average total protein content of the Beggiatoa enrichment; $\mu \mathrm{g} /$ tube) over time (d). Day $0=$ inoculum. Error bars indicate SE $(n=6)$
Fig. 2b,c). However, filaments of $2-6 \mathrm{~mm}$ in length occurred also during the whole experiment.

\section{FISH/DAPI and Light Microscopy}

An overlay of FISH and DAPI images shows regions along the filament in which neither ribosomes nor DNA occurred (Fig. 3a). Such "empty" regions were also visible in ordinary light micrographs (Fig. 3b).

\section{Filament Gliding Speed, Breakage, and Movement}

The average gliding speed of the Beggiatoa filaments was $3.2 \pm 0.1 \mu \mathrm{m} / \mathrm{s}$. Variation of the gliding speed over time was not observed, and the gliding speed did not depend on the position of the filaments in the gradient cultures.

Single filaments that were inoculated into new gradient tubes, started to break after 17.0 (movie 1), 23.5 (movie 2), and $15.6 \mathrm{~h}$ (movie 3; Fig. 4a-c). The next three to four filament breaks occurred during the following 3-16 h of incubation. Filament breakage can be roughly grouped into three types: (1) breakage of a stretched filament, (2) breakage at the tip of a filament loop, and (3) breakage at the position where formerly the tip of a loop was located (Fig. 5a-c). Furthermore, some of the breakages occur via separation of one or a few end cells, where a hormogonium may have been produced, and sometimes it was observed that two parts of formerly one filament continued to share their slime sheath for approximately 1 min before separation.

\section{Discussion}

The increase of the total protein content of the Beggiatoa enrichment was linear for as long as 14 days because growth was most probably limited by the sulfide flux in gradient cultures (Fig. 1). This argumentation is based on a study of Nelson et al. [18] who also initiated the growth of marine Beggiatoa by inoculation of replicate gradient culture tubes to investigate the linear increase of protein content. In parallel to the protein determination, these authors measured also microsensor profiles of sulfide in the gradient tubes, and found that the linear increase of Beggiatoa biomass was accompanied by an essentially constant sulfide flux. Thus, they concluded that sulfide availability limited growth. In addition, the protein determination of Nelson et al. [18] revealed that linear growth occurred only after an initial period of exponential biomass increase (cell doubling time of $11 \mathrm{~h}$ ), because sulfide was not limiting during the initial growth phase. During our experiments, an initial exponential growth of Beggiatoa was not resolved by measuring the total protein content probably owing to the time schedule of sampling. However, 


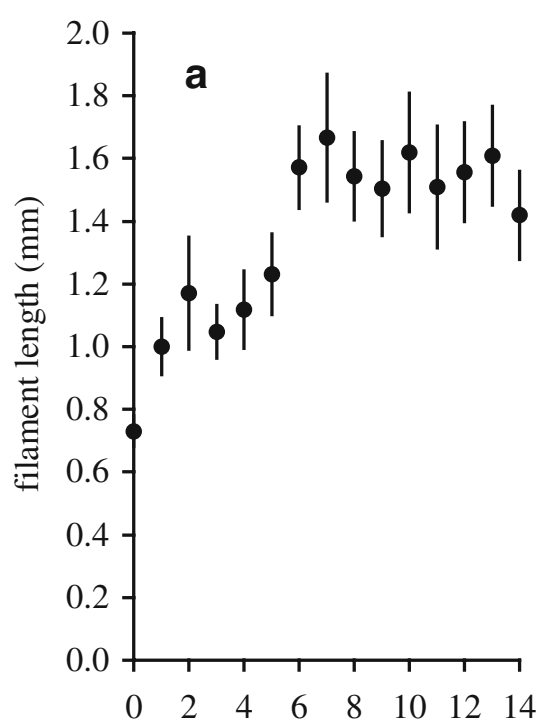

time $(\mathrm{d})$

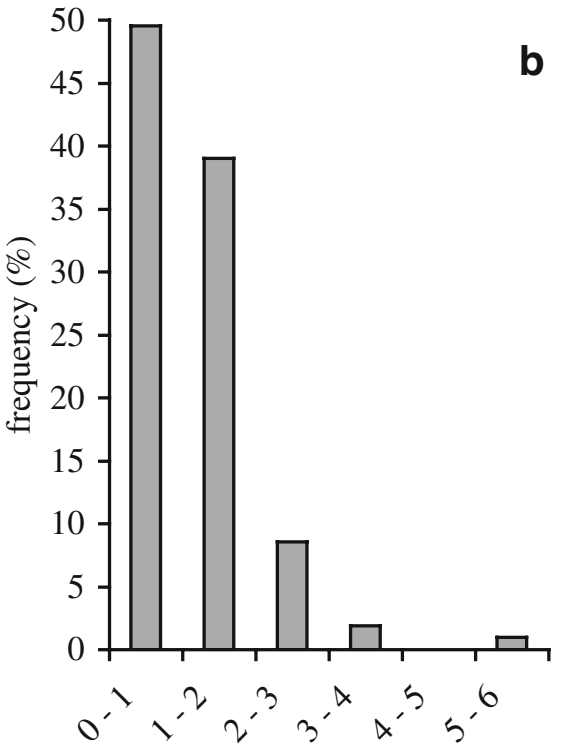

filament length (mm)

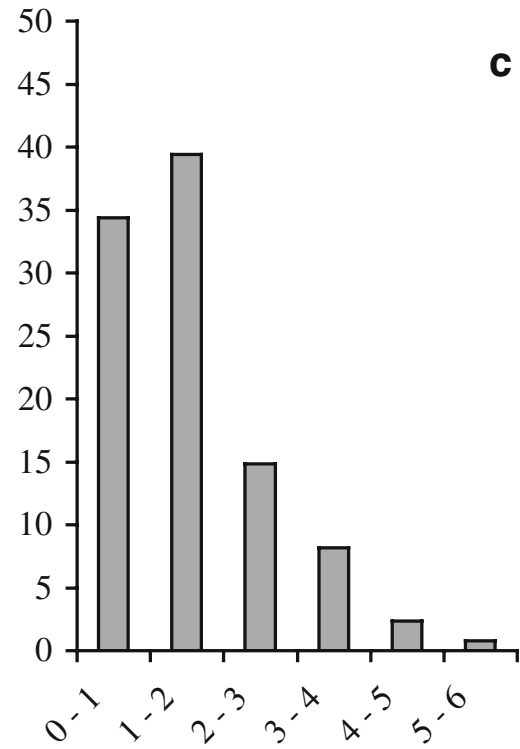

filament length (mm)

Figure 2 (a) Average Beggiatoa filament length $(\mathrm{mm})$ over time (d). Day $0=$ inoculum. Error bars indicate SE $(n=42)$. $(\mathbf{b}, \mathbf{c})$ Frequency $(\%)$ of Beggiatoa filament lengths in classes of $1 \mathrm{~mm}$, averaged for day $1-5(n=210 ; \mathbf{b})$ and for day $6-14(n=378 ; \mathbf{c})$

we determined the initial cell doubling time of Beggiatoa in separate gradient tubes, which were inoculated with only one filament. Here, the competition between several filaments for sulfide was very unlikely, and exponential growth must have been given during the initial growth phase. However, the initial doubling time which we calculated for Beggiatoa cells $(15.7 \pm 1.3 \mathrm{~h})$ must be seen as a potential that is valid only until sulfide becomes limiting.

The average filament length in the inoculum was remarkably short (Fig. 2a) and was most likely the result of mechanical disruption of Beggiatoa filaments during the thorough mixing of the inoculum before inoculation. This procedure was essential to obtain identical subsamples for the inoculation of replicate culture tubes. However, filament disruption through mixing did not impair the overall viability of the Beggiatoa filaments, as indicated by the immediate growth of the cultures after inoculation. The filament length determination on objective slides clearly documented that the Beggiatoa filaments grew up to an average length that remained constant (approximately $1.7 \mathrm{~mm}$ ). Further, the frequency distribution of classes of filament lengths (Fig. 2b,c) revealed that filaments of up to $2 \mathrm{~mm}$ in length were equally common during the early and the later incubation period, and that filaments of $2-6 \mathrm{~mm}$ in length occurred with low frequency during the whole experiment. The growth of the Beggiatoa culture was thus not achieved by ever growing filaments, but by alternating filament elongation and breakage that controlled the average filament length. The constant average filament length could possibly be an invariable trait of the investigated Beggiatoa sp., or it could be influenced by environmental conditions, e.g., by the availability of sulfide, or the physical structure of the habitat. Field studies in the sediments of a brackish fjord (Limfjorden, Denmark) revealed that the average filament length of Beggiatoa spp.
Figure 3 (a) Beggiatoa filaments hybridized with the universal Bacteria probe EUB338-III (FISH) and counterstained with DAPI, showing regions along the filament that neither hybridized to the FISH probe, nor were stained with DAPI. (b) Light micrograph of Beggiatoa filaments, showing an "empty" region where a cell lysed. Bars, $10 \mu \mathrm{m}$
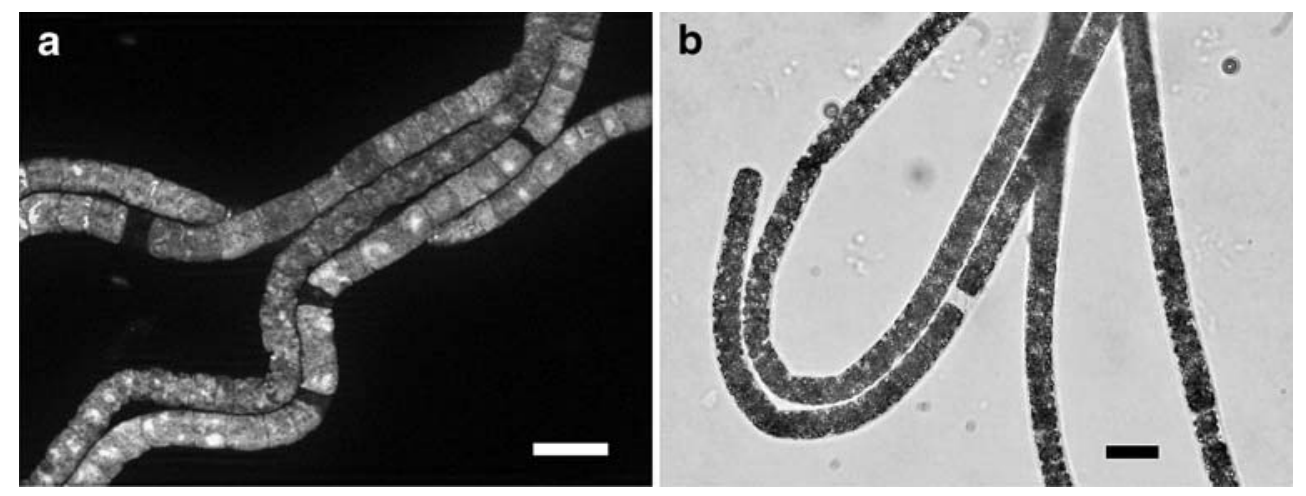
Figure 4 First filament breakages observed after inoculation. Time after inoculation (h) and filament length $(\mathrm{mm})$ were taken from movies 1(a), 2 (b), and 3 (c). Arrows with continuous lines show filament breakage (black filaments); arrows with dashed lines show filament growth (gray filaments)

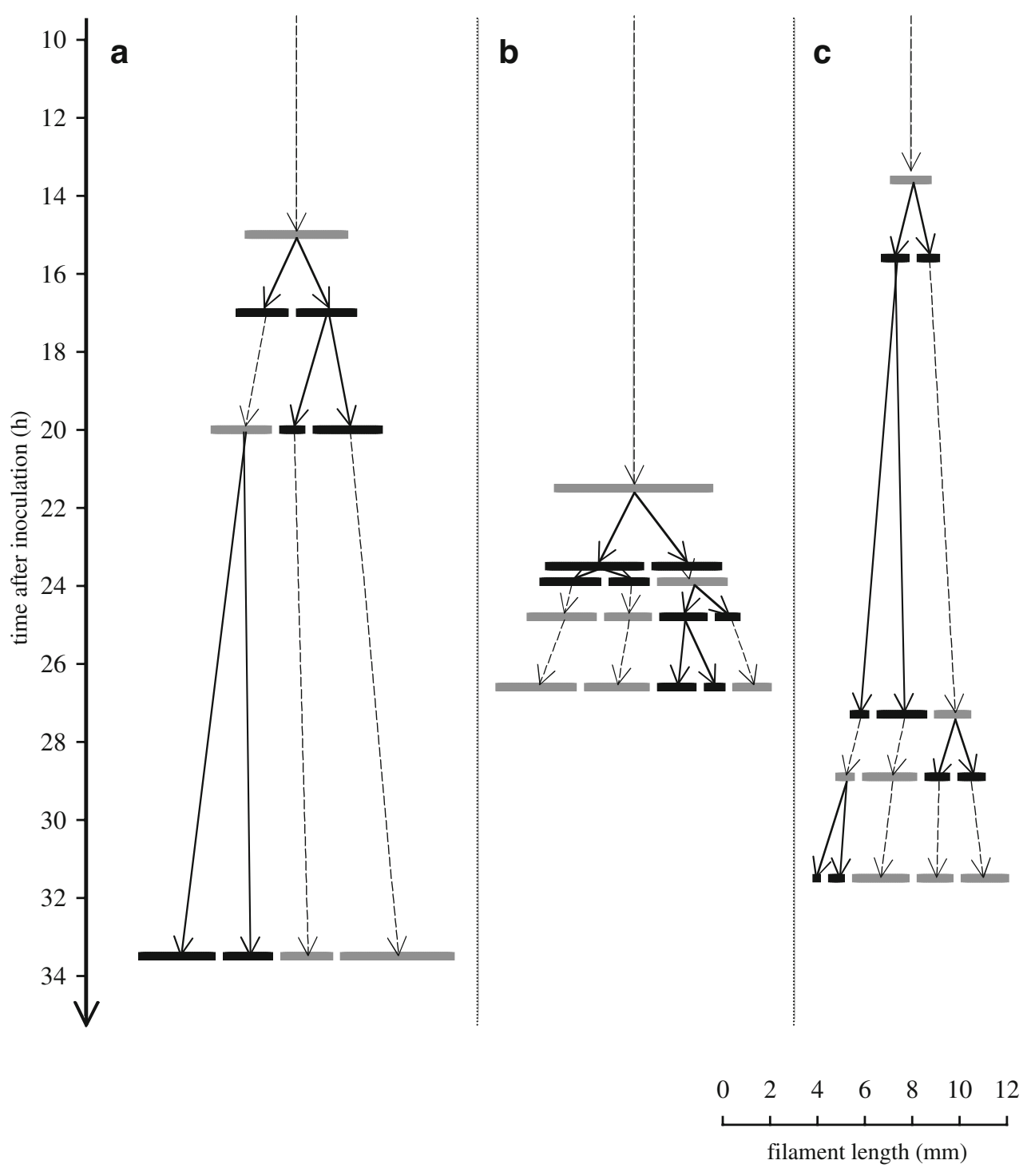

was positively correlated with the filament width [10]. In this sediment, Beggiatoa spp. with filament widths that were comparable to the Beggiatoa sp. investigated by us, had an average filament length of $1.0 \mathrm{~mm}$ and were thus considerably shorter than the average filament length of $1.7 \mathrm{~mm}$ we determined. According to Jørgensen [10], the grain size of sediments has an impact on the distribution of Beggiatoa. Perhaps, it is also possible that growth of filament length in soft agar was enhanced compared to more compact sediments in which the interstitials could be space-limiting.

The "empty regions" along the filament that were detected with a combination of FISH and DAPI staining and with light micrographs (Fig. 3a,b) showed regions where one or a few cells have lysed. It is known that Beggiatoa filament breakage is accomplished by formation of sacrificial cells (necridia) at various points within the filament. Upon dying, the sacrificial cells lyse, dividing the filament into daughter filaments. This process has been schematically illustrated by Strohl and Larkin [24] and is comparable with filament breakage in the filamentous cyanobacterium Oscillatoria [12]. The mechanism that controls the formation of necridia in Beggiatoa is still unclear. However, timelapse movies provided examples of the time course of filament breakage and the position at which the filaments break (Fig. 4a-c). It took approximately $19 \mathrm{~h}$ after inoculation before first filament breakages occurred. The paradox that optimal growth conditions leads to cell death is plausible because the breakage into daughter filaments facilitates multiplication. Further, the time-lapse movies illustrate that a filament may not only break once into two daughter filaments, but a couple of times within a short time period so that several daughter filaments can occur within a few hours. An explanation for this could be the relatively simultaneous induction of the death of several sacrificial cells inducing the multiple breakage of the filament. 

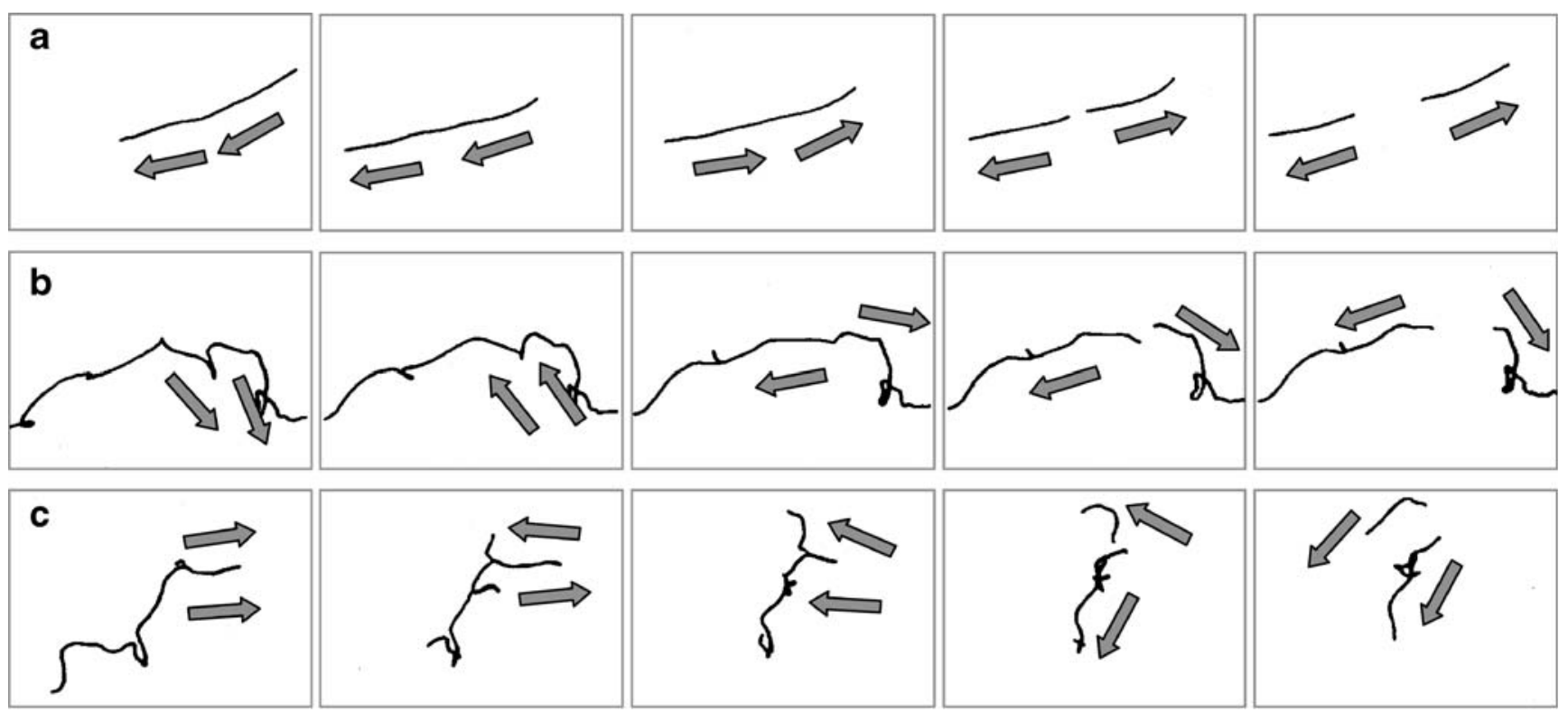

Figure 5 Series of single picture as examples of filament breakage types. (a) Breakage in the middle of a stretched filament. (b) Breakage at the tip of a filament loop. (c) Breakage at the position where formerly a tip of a loop was located. Arrows indicate direction of filament movement. Filaments were redrawn manually from movie images. Corresponding movies can be found in the supplementary material
The time-lapse movies allowed also the observation of gliding directions in breaking filaments. The following patterns were observed: (1) If the filament breakage occurred in a stretched filament, the two parts of one filament usually glided in the same direction before the breakage and away from each other after the breakage (Fig. 5a; corresponding movie can be found in the supplementary material). (2) If the filament breakage occurred at the tip of a loop, or at the position where formerly the tip of a loop was located, the two parts of one filament moved toward each other before the breakage, whereby the loop was formed, and away from each other after the breakage (Fig. 5b,c; corresponding movies can be found in the supplementary material). In $>20 \%$ the filaments broke at the tip of a former loop. If breakage would occur at random positions, only a value of $0.16 \%$ would be expected (given for a filament of average length with 630 cells). Thus, breakage occurs predominantly at the tip of former loops.

The gliding speed of the Beggiatoa $\mathrm{sp}$. was $3.2 \pm 0.1 \mu \mathrm{m} / \mathrm{s}$ and thus in the range of other Beggiatoa spp. from various habitats (i.e., $1-8 \mu \mathrm{m} / \mathrm{s}$ [23]). Gliding motility of Beggiatoa is often accompanied by flexing, bending, or rotation of the filaments [23]. Beggiatoa filaments can reverse the direction of movement in response to increasing oxygen concentrations [15]. This phobic response to oxygen is observed whenever either a filament tip or a filament loop glides into a stable microgradient of increasing oxygen concentration. In many cases, only a part of the filament responds, which leads to the formation of sharp bends or loops within the filament. According to Møller et al. [15], this partial response facilitates the positioning of filaments at the oxygen-sulfide interface, the microhabitat of Beggiatoa. The biochemical nature of the cellular response that controls the direction of movement of filaments is not known until now. Further, a possible mechanism of communication between cells, which could mediate the biochemical control of loop formation, has not been identified. However, beside a proposed biochemical mechanism that controls the movement directions of Beggiatoa, the observed co-occurrence between loop formation and filament breakage could be also explained by an interruption of communication, e.g., because of a sacrificial cell. In this case, two parts of one filament, which share one common slime sheath, could act independently of each other, which increases the probability of opposite directions of movement. If the movement direction is toward each other, a loop will be formed. After loop formation, filament breakage can occur when the two independently acting parts of one filament, both change their gliding direction, and move away from each other. An additional explanation for the co-occurrence of loop formation and filament breakage could be that loops were formed at random positions and that the strong mechanical forces at the tip of the loop led to necridia at this position, and that, finally, filament breakage occurred predominantly at positions with sacrificial cells. Also in this case, it is unlikely that the two parts of one filament separated by a 
sacrificial cell can communicate with each other. Thus, we hypothesize that the occurrence of sacrificial cells enhances the probability of loop formation.

Video-supported analysis of Beggiatoa in combination with culture techniques in transparent agar represents a powerful method for side view observations of filament growth, breakage, and movement. This method has the advantage that the Beggiatoa can be observed exactly in their typical habitat of opposite gradients of oxygen from above and sulfide from below, which is an addition to the top view images of Beggiatoa that were possible in the sediment [Dunker R (2005) Microsensor studies on a Beggiatoa mat under changing oxygen concentrations. MSc thesis, University of Bremen, Germany]. Further studies should combine the video-supported analysis with microsensor measurements in gradient cultures $[11,19]$. The correlation of the exact position of the filaments to the vertical gradients of oxygen and sulfide could lead to further insight into the mechanism that enables the filaments to respond to the chemical parameters of their microenvironment.

Acknowledgments S. Viehmann collected the Beggiatoa sp. that was enriched in gradient culture by H. N. Schulz-Vogt in the laboratory of D. C. Nelson. P. Stief is gratefully acknowledged for the initial idea of making these movies and the critical reading of the manuscript. L. P. Nielsen and B. B. Jørgensen are thanked very much for fruitful discussions. M. B. Lund gave valuable help with FISH. M. Schubert and P. Stolle are thanked for technical support. The anonymous reviewers are acknowledged for their constructive suggestions that helped to improve the manuscript. This study was funded by grant SCHU1416/2-1 from the Deutsche Forschungsgemeinschaft (German Research Foundation) and by the Max Planck Society, Germany.

\section{References}

1. Amann RI, Ludwig W, Schleifer KH (1995) Phylogenetic identification and in situ detection of individual microbial cells without cultivation. Microb Rev 59:143-169

2. Bradford MM (1976) A rapid and sensitive method for the quantitation of microgram quantities of protein utilizing the principle of protein-dye binding. Anal Biochem 72:248-254

3. Daims H, Brühl A, Amann R, Schleifer K-H, Wagner M (1999) The domain-specific probe EUB338 is insufficient for the detection of all Bacteria: development and evaluation of a more comprehensive probe set. Syst Appl Microbiol 22:434-444

4. Garcia-Pichel F, Mechling M, Castenholz RW (1994) Diel migrations of microorganisms within a benthic, hypersaline mat community. Appl Environ Microbiol 60:1500-1511

5. Gundersen JK, Jørgensen BB, Larsen E, Jannasch HW (1992) Mats of giant sulfur bacteria on deep-sea sediments due to fluctuating hydrothermal flow. Nature 360:454-455

6. Halfen LN, Castenholz RW (1971) Gliding motility in blue-green alga, Oscillatoria princeps. J Phycol 7:133-145

7. Hoiczyk E (2000) Gliding motility in cyanobacteria: observations and possible explanations. Arch Microbiol 174:11-17
8. Hoiczyk E, Baumeister W (1998) The junctional pore complex, a prokaryotic secretion organelle, is the molecular motor underlying gliding motility in cyanobacteria. Curr Biol 8:1161-1168

9. Jannasch HW, Nelson DC, Wirsen CO (1989) Massive natural occurrence of unusually large bacteria (Beggiatoa sp.) at a hydrothermal deep-sea vent site. Nature 342:834-836

10. Jørgensen BB (1977) Distribution of colorless sulfur bacteria (Beggiatoa spp.) in a coastal marine sediment. Mar Biol 41:19-28

11. Kamp A, Stief P, Schulz-Vogt HN (2006) Anaerobic sulfide oxidation with nitrate by a freshwater Beggiatoa enrichment culture. Appl Environ Microbiol 72:4755-4760

12. Lamont HC (1969) Sacrificial cell death and trichome breakage in an oscillatoriacean blue-green alga: the role of murein. Arch Mikrobiol 69:237-259

13. Larkin JM, Henk MC (1996) Filamentous sulfide-oxidizing bacteria at hydrocarbon seeps of the Gulf of Mexico. Microsc Res Tech 33:23-31

14. McHatton SC, Barry JP, Jannasch HW, Nelson DC (1996) High nitrate concentrations in vacuolate, autotrophic marine Beggiatoa spp. Appl Environ Microbiol 62:954-958

15. Møller MM, Nielsen LP, Jørgensen BB (1985) Oxygen responses and mat formation by Beggiatoa spp. Appl Environ Microbiol 50:373-382

16. Nelson DC, Castenholz RW (1982) Light responses of Beggiatoa. Arch Microbiol 131:146-155

17. Nelson DC, Jannasch HW (1983) Chemoautotrophic growth of a marine Beggiatoa in sulfide-gradient cultures. Arch Microbiol 136:262-269

18. Nelson DC, Jørgensen BB, Revsbech NP (1986) Growth pattern and yield of a chemoautotrophic Beggiatoa sp. in oxygen-sulfide microgradients. Appl Environ Microbiol 52:225-233

19. Nelson DC, Revsbech NP, Jørgensen BB (1986) Microoxicanoxic niche of Beggiatoa spp.: microelectrode survey of marine and freshwater strains. Appl Environ Microbiol 52:161-168

20. Richardson LL (1996) Horizontal and vertical migration patterns of Phormidium corallyticum and Beggiatoa spp. associated with black-band disease of corals. Microb Ecol 32:323-335

21. Sayama M (2001) Presence of nitrate-accumulating sulfur bacteria and their influence on nitrogen cycling in a shallow coastal marine sediment. Appl Environ Microbiol 67:3481-3487

22. Stahl DA, Amann R (1991) Development and application of nucleic acid probes. In: Stackebrandt E, Goodfellow M (eds) Nucleic acid techniques in bacterial systematics. John Willey \& Sons Ltd, Chichester, UK, pp 205-248

23. Strohl WR (2005) Beggiatoa. In: Brenner DJ, Krieg NR, Staley JT, Garrity GM (eds) Bergey's manual of systematic bacteriology. vol. vol 2. 2nd ednd edn. Springer, New York, pp 148-161

24. Strohl WR, Larkin JM (1978) Cell division and trichome breakage in Beggiatoa. Curr Microbiol 1:151-155

25. Sweerts JPRA, De Beer D, Nielsen LP, Verdouw H, Van den Heuvel JC, Cohen Y, Cappenberg TE (1990) Denitrification by sulfur oxidizing Beggiatoa spp. mats on fresh-water sediments. Nature 344:762-763

26. Teske A, Nelson DC (2006) The genera Beggiatoa and Thioploca. In: Dworkin M, Falkow S, Rosenberg E, Schleifer K-H, Stackebrandt E (eds) Prokaryotes,. vol. vol 6. 3rd edrd edn. Springer, New York, pp 784-810

27. Trevisan V (1842) Prospetto della Flora Euganea. Coi Tipi Del Seminario, Padova, pp 1-68

28. Vaucher JP (1803) Histoire des conferves d'eau douce, contenant leurs différents modes de reproduction, et la description de leurs principales espèces. JJ Paschoud, Geneva, pp 1-285 